\title{
Board 84: Associations between Veteran and Non-Veteran Student Percep- tions of Social Responsibility
}

\section{Dr. Stacey E. Kulesza, Kansas State University}

Dr. Stacey Kulesza is an assistant professor in the civil engineering department at Kansas State University. Dr. Kulesza teaches undergraduate and graduate courses in geotechnical engineering and is a licensed engineer in the state of Kansas.

\section{Dr. Jia G. Liang, Kansas State University}

Jia Grace Liang is a faculty in the Department of Educational Leadership at Kansas State University (USA). Her research interests focus on school leadership, professional development and learning in STEM, equity for women and racial minorities, and leadership for community engagement. She holds a PhD from the University of Georgia in Educational Administration and Policy.

\section{Dr. Eric J. Fitzsimmons, Kansas State University}

Dr. Eric Fitzsimmons, P.E. is an assistant professor in the civil engineering department at Kansas State University. He received his B.S., M.S., and Ph.D. degrees in Civil Engineering with a specialization in transportation from Iowa State University. Dr. Fitzsimmons is a graduate of the American Society of Civil Engineers Excellence in Civil Engineering Education (ExCEED) and also has served as an assistant mentor. He teaches undergraduate and graduate courses in transportation and railroad engineering.

\section{Dr. Jeff Zacharakis, Kansas State University}

Jeff Zacharakis is a professor of adult learning and leadership in the Department of Educational Leadership. His areas of research include leader and organizational development.

\section{Mr. Jeffrey Chase Hood MA, Kansas State University}

J. Chase Hood is a doctoral student in the Department of Psychological Sciences at Kansas State University. He studies cognitive psychology, experimental design, statistical analyses, and seeks to apply his research to improving education. 


\section{Associations between Veteran and Non-Veteran Student Perceptions of Social Responsibility}

Introduction

This research aims to address the global initiative to increase diversity in the engineering work force [1]. The U.S. military Veteran student population was identified as one of the most diverse student groups in engineering; however, discontinue and dismissal rates of Veteran students in engineering were significantly higher than traditional engineering students in the U.S. [2]. These Veteran students hold identifiable traits that differ from traditional engineering students who are under the age of 24 and financially dependent on their parents [3]. While a significant effort by institutions across the country have been made in engineering student retention, many of these efforts have focused on traditional students. This research seeks to fill this gap by specifically addressing the retention of Veteran students using the concept of social responsibility. Social responsibility is generally considered to be acting to benefit society. It is a common ideal promoted in the military (e.g., service before self in the U.S. Air Force fundamental and enduring values). It is also embodied in the engineer's creed (i.e., engineers using their professional skills to improve human welfare) and revealed by the literature as a key factor that attracts many students from historically underrepresented groups into engineering [4]. Therefore, the objective of this research was to explore if veteran student perceptions of social responsibility was consistent with prior research.

A survey instrument was developed at a 4-year land-grant institution based on a model for assessing first-year engineering student understanding of social responsibility [5]. The survey was updated to include demographics specific to the Veteran student cohort (e.g., military branch, prior job attributes, and university transfer credits) and questions specifically linking military service and engineering. The results of this research will be used to design an intervention strategy, likely in the first-year when most Veteran students discontinue or are dismissed, to increase Veteran retention in engineering programs.

\section{Methodology}

A modified version of the professional social responsibility development model (PRSDM), developed by Canney and Bielefeldt [5], was used in this study. The pilot study methodology was described by Tucker-Kulesza et al. [6]. The pilot survey was sent to 15 students who selfidentified as Veterans in their student profiles and 30 non-Veteran first year students in engineering. Students were selected via a random number generated from two separate LISTSERVs and were provided a monetary incentive to participate. Several attempts were made to obtain the target number of Veteran and non-Veteran first year students, specifically regarding the response of the first-years [6]. Ultimately, the pilot survey was taken by 15 first-year and 11 Veteran students. Thus, the research methodology was modified to capture a larger cohort of first-year students for the full survey launch. The authors made an announcement in most of the first-year introductory engineering courses when the full survey was launched. This reduced the perception of a scam and provided an avenue for the authors to introduce the study (described as interest in improving engineering student retention in their first year) to this cohort. 
Survey respondents were asked if they were willing to participate in a follow-up focus group discussion regarding the survey, for further compensation. Due to scheduling circumstances, a one-to-one interview (1 Veteran student) and one focus group interview (4 Veteran, 1 nonVeteran first-year) were scheduled following the survey. The interviews were semi-structured formal interviews [7] used to review the student's perception of the survey and if any modifications were needed.

The revised survey was launched to all students in the college of engineering who self-identify as Veterans and all first-year students. Data were analyzed for internal consistency of the PRSDM scales via Cronbach's alphas [8]. Cronbach's alpha was calculated using the items corresponding to each of the underlying factors of social responsibility (i.e., social awareness, professional development, and professional connectedness) as well as for the scale as a whole. An exploratory factor analysis [9] was conducted to determine if the survey items load on the three factors (i.e., social awareness, professional development, and professional connectedness) as intended according to the PSRDM. Finally, T-tests were conducted to compare the Veteran and nonVeteran students on each subscale and the overall PSRDM scale. The survey also asked students to list faculty who include concepts of social responsibility in their classes. These instructors needed not be engineering faculty.

Results and Discussion

The pilot survey results were described by Tucker-Kulesza et al. [6]. Changes were made to the survey following the focus group discussion, where students reviewed the survey and discussed confusing language question by question. Discussions involved updating questions for clarity. For example, the initial survey stated that "Service should not be an expected part of the engineering profession." Participants noted that this particular question was ambiguous, was the question interested in community service, professional service, or military service? There was also significant discussion regarding the definition of community, "There are needs in my community." The focus group suggested that most would not think there are needs in their community and suggested examples of "community needs." Although the authors agreed that these were valid points, the questions were not changed because of the validity of the original survey. It was decided these questions were intentionally vague.

Several changes were made regarding language in the military service questions, which were noted as potential triggers for Veteran students. The focus group indicated many Veterans would not feel comfortable answering specific questions regarding their military service and, if these details were not critical to the research, modifications would improve the survey. Also, it was not clear in the pilot survey that questions could be skipped without penalty. For example, the original survey requested their Military Occupational Specialties (MOS). While $86 \%$ of the Veterans who participated in the survey were members of the U.S. Army, this is an Army specific term and was identified as unacceptable terminology. Also, focus group participants indicated they were not comfortable giving exact service codes and suggested the question be more generalized. Another example of a modified question was, "Did you have combat experience?" Similar feedback indicated that the same general information could be obtained by asking, "Were you deployed during your time in the military?" There were no suggested trigger 
questions which were critical to the statistical analysis regarding social responsibility, therefore four Veteran specific questions were modified as suggested and shown in Table 1.

Table 1. Veteran specific survey updates

\begin{tabular}{|l|l|}
\hline Pilot Survey & Full Survey \\
\hline $\begin{array}{l}\text { Prior to coming to (4-year land } \\
\text { grant institution), what were your } \\
\text { military occupational specialties } \\
\text { (MOS)? Please list all including the } \\
\text { title, number, and identify your last } \\
\text { MOS. }\end{array}$ & $\begin{array}{l}\text { Prior to coming to (4-year land grant institution), what } \\
\text { were your primary roles/jobs in the military (e.g., } \\
\text { infantry, communications equipment technician, } \\
\text { environmental). In other words, please give a general } \\
\text { title that fits the jobs you had or roles you filled. }\end{array}$ \\
\hline Years of military service? & How long did you serve in Active Duty? \\
Answer: Active duty (open ended) & $\begin{array}{l}\text { Answer: Less than 5 years; Five to ten years; More than } \\
\text { ten years }\end{array}$ \\
\cline { 2 - 2 } Answer: Reserves (open ended) & How long did you serve in the Reserves? \\
& $\begin{array}{l}\text { Answer: Less than 5 years; Five to ten years; More than } \\
\text { ten years; Did not serve. }\end{array}$ \\
\hline Did you have combat experience & Were you deployed during your time in the military? \\
\hline
\end{tabular}

The survey was launched October 2018 to all students who self-identified as Veterans and all first-year students in the college of engineering at a 4-year land grant institution. As expected, the initial survey launch had limited responses from first-year students (12\% by survey closing date). Thus, the authors made an announcement in six of the nine first year classes. One engineering major (biological and agricultural engineering) did not have a weekly first-year course in fall 2018. Two engineering majors (architectural engineering and industrial and manufacturing systems engineering) could not be announced due to scheduling conflicts. The authors also sent second round of individual emails to Veteran students who had not participated in the survey by the closing date. The survey closing date was extended by one week after all announcements and follow up emails. Ultimately, 44\% of the Veteran student cohort and 52\% of the non-Veteran first-year cohort responded to the survey.

The results of the study indicated that the modified survey items loaded on the three factors (i.e., social awareness, professional development, and professional connectedness) according to the PSRDM by use of the exploratory factor analysis. This was true for the individual cohorts (i.e., Veteran students and first-year students) and the combined cohort. The consistency of the PSRDM scale was validated by Cronbach's alphas. Cronbach's alpha values can vary between 0 and 1 and can theoretically be negative. A minimum 0.6 alpha was required to indicate consistency, therefore, as shown in Table 2, the revised survey was valid across all factors and the overall scale. 
Table 2: Survey internal consistency

\begin{tabular}{|l|l|}
\hline Factor & Alpha \\
\hline Social awareness & .65 \\
\hline Professional development & .85 \\
\hline Professional connectedness & .69 \\
\hline Overall scale & .85 \\
\hline
\end{tabular}

The results of this study also indicated that there was no statistically significant difference between the Veteran cohort and the first-year cohort in terms of their perceptions of social responsibility $(p>.05)$, with both groups measuring high on the social responsibility scale $(M=$ 4.00, $S D=0.35$ ). This implies that Meyers and Mertz [4] research on first-year students is also consistent with this Veteran cohort. Therefore, this supports the hypothesis that social responsibility emphasized in the military can be extended to engineering students who are Veterans. The study also validated the research of others in that of the cohort as a whole that women $(M=4.09, S D=0.32)$ have higher social responsibility than men $(M=4.00, S D=0.35)$, $t(422)=2.73, p=.007$ [5]. Finally, there were no significant differences in social responsibility scores between students of different engineering majors. It was believed that majors with greater social responsibility aspects (e.g., civil engineering, biomedical engineering) would have students who were more motivated by social responsibility, but this was not found in this study.

Future Work

The authors are currently scheduling interviews with individual faculty identified by students and another group of Veteran students. The focus-group interviews with the Veteran engineering students and individual faculty interviews will focus on gathering the following qualitative data:

(1) How do Veteran students define social responsibility in relation to the three tenets suggested by the PSRDM model?

(2) How do faculty who are the instructors of the courses identified by the survey results as containing social-responsibility elements define social responsibility?

a. How have the faculty's definitions of social responsibility informed and shaped their curricular and pedagogical practices?

(3) How have Veteran students' orientation to social responsibility influenced their first-year experiences?

a. How have the students' orientation to social responsibility influenced their expectations of academic curricular?

b. How have the students' orientation to social responsibility influenced their expectations of faculty engagement? 
A thematic analysis will be used to analyze the interview data [10]. The results of the survey and thematic analysis will be used to propose several interventions, with a target fall 2019 implementation.

\section{References}

[1] National Academies of Sciences, Engineering, and Medicine, "Quality in the Undergraduate Experience: What Is It? How Is It Measured? Who Decides? Summary of a Workshop," The National Academies Press, Washington, D.C., 2016.

[2] B. Cook and Y. Kim, "From soldier to student: Easing the transition of service members on campus," Lumina Foundation for Education, Washington, D.C., 2009.

[3] A. Radford, Military service members and veterans in higher education: What the new GI bill may mean for postsecondary institutions, New York: American Council on Education, 2009.

[4] K. Meyers and B. Mertz, "A large scale analysis of first-year engineering student essays on engineering interests," in ASEE Annual Conference and Exposition, Washington, D.C., 2011.

[5] N. Canney and A. Bielefeldt, "Validity and reliability evidence of the engineering professional responsibility assessment tool," J. Engineering Education, vol. 105, no. 3, pp. 452-477, 2016.

[6] S. Tucker-Kulesza, G. Liang, E. Fitzsimmons, J. Zacharakis, "Work in Progress: Investigating the Role of Social Responsibility on Veteran Student Retention," in ASEE Annual Conference and Exposition, Salt Lake City, Utah, 2018.

[7] I. Seidman, Interviewing as qualitative research: A guide for researchers in education and the social sciences, New York: Teachers College Press, 2006.

[8] J. M. Cortina, "What is coefficient alpha? An examination of theory and applications," J. Appl. Psychol., vol. 78, no. 1, pp. 98-104, 1993.

[9] A. Costello and J. Osborne. "Best Practices in Exploratory Factor Analysis: Four Recommendations for Getting the Most from Your Analysis," Practical assessment, research \& evaluation, vol. 10, no 7, pp. 1-9, 2005.

[10] V. Braun and V. and Clarke, "Using thematic analysis in psychology," Qualitative Research in Psychology, vol. 3, no. 2, pp. 77-101, 2006. 